\title{
ITCH regulates oxidative stress induced by high glucose through thioredoxin interacting protein in cultured human lens epithelial cells
}

\author{
LINGFENG JIANG, WENKAI ZHOU, BO LU and QICHANG YAN
}

\begin{abstract}
Department of Ophthalmology, Fourth Affiliated Hospital of China Medical University, Ophthalmology Hospital of China Medical University, Key Laboratory of Lens in Liaoning Province, Shenyang, Liaoning 110005, P.R. China
\end{abstract}

Received January 20, 2020; Accepted July 22, 2020

DOI: $10.3892 / \mathrm{mmr} .2020 .11499$

\begin{abstract}
Thioredoxin (Trx) is an important protein that controls oxidative damage in almost all eukaryotic cells. Trx interaction protein (Txnip) has been reported to negatively regulate the bioavailability of $\operatorname{Trx}$ and inhibit its biological function. The E3 ubiquitin ligase ITCH can specifically degrade Txnip via ubiquitination. The apoptosis of human lens epithelial cells (HLECs), which are highly sensitive to redox caused by oxidative stress, is a significant factor for the development of sugar cataract in a high-glucose environment. However, whether Trx, Txnip and ITCH contribute to the progression of sugar cataracts and the underlying mechanisms remain unknown, and thus, identifying these were the aims of the present study. The present results suggested that the expression levels of Trx, Txnip and ITCH in HLECs cultured with different glucose concentrations were detected by reverse transcription-quantitative PCR and western blotting, and the apoptotic rate of the cells was detected by flow cytometry and superoxide detection assay. The interaction between ITCH and Txnip was determined by co-localization immunofluorescence and co-immunoprecipitation. In addition, a vector and small interfering RNA of ITCH were transfected to overexpress and knockdown ITCH, respectively, to alter the expression of downstream proteins and cell apoptosis. It was found that Txnip was highly expressed in cultured HLECs in high-glucose environment, and the antioxidative function of Trx was restricted and suppressed, thus promoting apoptosis. The overexpression of ITCH increased the expression of Trx and decreased oxidative stress and apoptosis by decreasing
\end{abstract}

Correspondence to: Dr Qichang Yan, Department of Ophthalmology, Fourth Affiliated Hospital of China Medical University, Ophthalmology Hospital of China Medical University, Key Laboratory of Lens in Liaoning Province, 11 Xinhua Road, Heping, Shenyang, Liaoning 110005, P.R. China

E-mail: cmu4h-yqc@126.com

Key words: thioredoxin, thioredoxin interaction protein, ITCH, oxidative stress, ubiquitination, sugar cataract
Txnip in cultured HLECs, while downregulation of ITCH significantly decreased the expression of Trx and enhanced oxidative stress and apoptosis. Therefore, the present results indicated that ITCH could regulate the apoptosis of HLECs that were cultured in high-glucose concentration and that it may be a treatment target for sugar cataract.

\section{Introduction}

Cataract is the most common eye disease that can lead to blindness worldwide and is associated with several factors, such as aging, genetic, malnutrition, immune and metabolic abnormalities, trauma, radiation and poisoning (1). Separately or combined, these factors induce high levels of lens epithelial cell apoptosis, which ultimately results in cataract, which affects the eyesight of the patients to some extent (2). With regards to the risk factors of cataract, metabolic diseases, especially diabetes, have become the second most important factor, with age being the first, gradually increasing the incidence of cataracts $(3,4)$. Previous studies have shown that reactive oxygen species (ROS) also play an important role in the development of sugar cataract $(5,6)$.

Thioredoxin (Trx), which combats against oxidative damage, is widely distributed in the human body (7). Trx exists in almost all eukaryotic cells and maintains the homeostasis of the organism against oxidative damage caused by ROS (8). Trx contains disulfide/dithiol, which acts as an active site for redox reactions, making it a scavenger of ROS (9). Another protein, thioredoxin interacting protein (Txnip), is closely linked to Trx in human HL-60 cells and can give rise to 1,25-vitamin D3 gene expression in high quantities, and thus, is referred to as vitamin D3 upgrade protein (VDUP) (10). Previous studies have also revealed the interaction between Trx and Txnip using yeast two-hybrid method (11). Txnip serves a negative regulatory role by changing the Trx disulfide bond conformation via binding itself onto the redox active site of Trx, greatly weakening the Trx redox function $(12,13)$. Furthermore, a high-glucose environment is a trigger of Txnip production (14).

The main role of ubiquitination is to degrade target proteins. Under the environment of high glucose, ubiquitination, as one of protein modification after translation, is very active (15). Therefore, it was speculated that the specificity 
of ubiquitin modification may degrade Txnip to restore the function of Trx. The process of ubiquitin degradation protein is a tertiary enzyme linked process: Ubiquitin activating enzyme-E1 makes a thioester bond with the carboxy-terminal glycine residue of ubiquitin. Then, the ATP-activated ubiquitin is transferred to ubiquitin conjugating enzyme-E2 via a covalent thioester linkage with the aid of E1 (16). Finally, ubiquitin ligase-E3 completes the transfer of activated ubiquitin onto the substrates and degrades them. There are only two types of E1 and a few types of E2, and both of these are abundant in vivo, which is similar to the ubiquitin molecules (17). However, the most important enzymes in this pathway are E3s, as they recognize specific substrates. E3 ubiquitin ligase, as the key regulator of target protein degradation in the ubiquitin-proteasome pathway, can specifically identify and bind to the substrate protein (18).

Atrophin-1 interacting protein 4 (AIP4) or ITCH gene was identified at the agouti locus in mouse coat color study and encodes a $113 \mathrm{kDa}$ HECT type Nedd4-like E3 ubiquitin ligase (19). Moreover, ITCH plays an important role in regulating apoptosis and other biological processes (19). It has also been shown that in myocardial cells, Txnip is a target protein of ubiquitin molecules (20). By interacting with E3 ligase-ITCH, Txnip protein expression is degraded by ubiquitin, thus reversing the degree of myocardial cell apoptosis caused by myocardial infarction (20). However, to the best of our knowledge, whether this mechanism can be applied in the model of sugar cataract has not been previously reported. Given that Txnip is a key factor of diabetes (14) and the effect of ITCH on Txnip degradation, this mechanism may be suitable for application in sugar cataracts, which are caused by oxidative stress.

In the present study, in order to explore the pathogenesis of sugar cataract, it was proposed that ITCH may regulate high glucose-induced oxidative stress through Txnip in sugar cataracts. Following which, the changes and interactions of Txnip, Trx and ITCH in human lens epithelia cells (HLECs) were examined in a high glucose environment. It was determined that oxidative stress was regulated through ITCH and altered the apoptosis of cells. This may help to identify a novel methods to guide clinical treatment and help the development of effective and high safety anti-cataract drugs.

\section{Materials and methods}

Cell culture and grouping. The human lens epithelial cell (HLEC) line (SRA01/04) was provided by the Ophthalmic Lens Key Laboratory of The Fourth Affiliated Hospital of the Chinese Medical University. Cells were incubated in DMEM (Gibco; Thermo Fisher Scientific, Inc.) with $25 \mathrm{mM}$ glucose (Sigma-Aldrich; Merck KGaA), 10\% FBS (Serana Europe, $\mathrm{GmbH}), 100 \mathrm{U} / \mathrm{ml}$ penicillin and $100 \mu \mathrm{g} / \mathrm{ml}$ streptomycin (Invitrogen; Thermo Fisher Scientific, Inc.), at $5 \% \mathrm{CO}_{2}$ saturation and $37^{\circ} \mathrm{C}$ in a cell incubator. When the cell confluence reached $\sim 70 \%$, the glucose concentration for cells was changed and cells were randomly divided into the following groups: Low-glucose group (LG; $5.5 \mathrm{mM}$ glucose concentration in culture); high-glucose 1 group (HG1; $12.5 \mathrm{mM}$ glucose concentration in culture); high-glucose 2 group (HG2; $25 \mathrm{mM}$ glucose concentration in culture); high-glucose 3 group (HG3;
$50 \mathrm{mM}$ glucose concentration in culture) and mannitol (Sangon Biotech Co., Ltd.) group (5.5 mM glucose concentration and $50 \mathrm{mM}$ mannitol in culture) The aforementioned culture conditions were used and cells were cultured for $24 \mathrm{~h}$. The original cells were treated with $50 \mathrm{mM}$ glucose for different incubation time (0, 6, 12 and $24 \mathrm{~h})(21)$.

$R N A$ extraction and reverse transcription-quantitative $P C R$ (RT-qPCR). Total RNA of each group of cells was extracted with the TRIzol ${ }^{\circledR}$ reagent (Takara Bio, Inc.) via centrifugation at 3,000 x $\mathrm{g}$ for $10 \mathrm{~min}$ at room temperature. After total RNA was quantified, RT was performed to synthesize cDNA using PrimeScript RT Master Mix (Takara Bio, Inc.). $\mathrm{RT}$ was conducted at $37^{\circ} \mathrm{C}$ for $15 \mathrm{~min}$ and $85^{\circ} \mathrm{C}$ for $5 \mathrm{sec}$. qPCR was conducted using cDNA, forward and reverse primers, SYBR Premix Ex TaqII (Takara Bio, Inc.) and ROX Reference Dye II (50X; Takara Bio, Inc.) under the following conditions: Initial denaturation at $95^{\circ} \mathrm{C}$ for $30 \mathrm{sec}$, followed by 40 cycles at $95^{\circ} \mathrm{C}$ for $5 \mathrm{sec}$ and $60^{\circ} \mathrm{C}$ for $34 \mathrm{sec}$. Relative expression levels of mRNA were calculated using the $2^{-\Delta \Delta \mathrm{Cq}}$ method (22).

The following primers were designed and synthesized to detect Trx, Txnip, ITCH and $\beta$-actin cDNA: Trx forward, 5'-TGTGGGCCTTGCAAAATGA-3'; Trx reverse, 5'-GGA ATATCACGTTGGAATACTTTTCA-3'; Txnip forward, 5'-ACCTGCCCCTGGTAATTGG-3'; Txnip reverse, 5'-TTC GGCTGGCCATGCT-3'; ITCH forward, 5'-ACCGGCTGC CATCTTAGTCT-3'; ITCH reverse, 5'-GGAAAACCTGAA GTTCTCACAGT-3'; $\beta$-actin forward, 5'-GTGGGGCGC CCAGGCACCA-3'; and $\beta$-actin reverse, 5'-CTCCTTAAT GTCACGCAGGATTTC-3'. Then, RT-qPCR amplification and analysis were performed using an Applied Biosystems 7500 RT-qPCR machine (Applied Biosystems; Thermo Fisher Scientific, Inc.). $\beta$-actin was used as the internal reference.

Western blotting. When cell confluence reached $\sim 90 \%$, total protein was extracted using RIPA protein lysis with PMSF (Beijing Solarbio Science \& Technology Co., Ltd.). After bicinchoninic acid (BCA; Wanleibio Co., Ltd.) measurement, the proteins (40 $\mu \mathrm{g} /$ lane) were added to 10\% SDS-PAGE (Nanjing KeyGen Biotech Co., Ltd.) and separated, and then transferred to PVDF membrane (EMD Millipore). After blocking with 5\% non-fat milk at room temperature for $2 \mathrm{~h}$, membranes were incubated overnight at $4^{\circ} \mathrm{C}$ with primary antibodies and secondary antibodies at room temperature for $2 \mathrm{~h}$. Antibody incubations were performed at the following dilutions: Trx (cat. no. ab26320; 1:5,000; Abcam), Txnip (cat. no. 14715s; 1:1,000; Cell Signaling Technology, Inc.), ITCH (cat. no. 12117s; 1:1,000; Cell Signaling Technology, Inc.), GAPDH (cat. no. 10494-1-AP; 1:5,000; ProteinTech Group, Inc.), caspase-3 (cat. no. 19677-1-AP; 1:5,000; ProteinTech Group, Inc.) and horseradish peroxidase-conjugated secondary antibodies against rabbit (cat. no. 10285-1-AP; 1:10,000; ProteinTech Group, Inc.). The blots were visualized using ECL (Thermo Fisher Scientific, Inc.) and an ECL system (Fluor Chem FC2, Alpha Innotech, Inc.) was used to visualize the bands. Densitometric analysis was performed by ImageJ software (version 1.8.0; National Institutes of Health). GAPDH was used to normalize the expression data. 
Immunofluorescence and co-immunofluorescence. Cells were plated into 24 -well plates at $5 \times 10^{4}$ cells per well and cultured for $24 \mathrm{~h}$. When the cell confluence reached $\sim 50 \%$, cells were fixed with $4 \%$ paraformaldehyde (Sangon Biotech Co., Ltd.) at room temperature for $30 \mathrm{~min}$ and solubilized in $0.1 \%$ Triton X-100 (Sangon Biotech Co., Ltd.) at room temperature for $10 \mathrm{~min}$. After blocking with 5\% non-fat milk at room temperature for $2 \mathrm{~h}$, the cells were incubated with primary antibodies at $37^{\circ} \mathrm{C}$ for $4 \mathrm{~h}$ and secondary antibodies at $37^{\circ} \mathrm{C}$ for $2 \mathrm{~h}$ in a dark environment. For immunofluorescence, the primary antibody of Trx were added, and for co-immunofluorescence, the primary antibodies of Txnip and Itch were added at the same time. Antibody incubations were performed at the following dilutions: Trx (cat. no. ab26320; 1:5,000; Abcam), Txnip (cat. no. 14715s; 1:100; Cell Signaling Technology, Inc.), ITCH (cat. no. sc-28367; 1:100; Santa Cruz Biotechnology, Inc.), donkey anti-mouse IgG highly cross-adsorbed secondary antibody-Alexa Fluor 488 (cat. no. A-21202; 1:2,000; Invitrogen; Thermo Fisher Scientific, Inc.) and goat anti-rabbit IgG highly cross-adsorbed secondary antibody-Alexa Fluor 594 (cat. no. A-11012; 1:1,000; Invitrogen; Thermo Fisher Scientific, Inc.). DAPI (Beyotime Institute of Biotechnology) was used for staining at room temperature for $3 \mathrm{~min}$. Subsequently, a fluorescence microscope (magnification, x400) was used to observe and collect the images.

Co-immunoprecipitation (COIP). Cells were plated at $5 \times 10^{6}$ cells per well into three dishes with $10-\mathrm{cm}$ diameter and cultured until cell confluence reached $\sim 100 \%$. Subsequently, total protein was extracted as aforementioned in the western blotting protocol and the protein concentration was determined using the BCA method. Total protein lysate, primary antibodies or IgG, incubation buffer (ProteinTech Group, Inc.) and Protein A sepharose beads slurry (ProteinTech Group, Inc.) were added into the spin columns and incubated at $4^{\circ} \mathrm{C}$ overnight. Subsequently, protein A sepharose beads slurry were added to the mixture for another incubation overnight at $4^{\circ} \mathrm{C}$. Antibody incubations were performed at the following dilutions: Txnip (cat. no. 14715s; 1:50; Cell Signaling Technology, Inc.), ITCH (cat. no. 12117s; 1:200; Cell Signaling Technology, Inc.), Trx (cat. no. ab26320; 1:5,000; Abcam) and IgG (cat. no. sc-2025; 1:100; Santa Cruz Biotechnology, Inc.). The products were washed with elution buffer (ProteinTech Group, Inc.) and mixed with Alkali neutralization buffer (ProteinTech Group, Inc.) and protein loading buffer (ProteinTech Group, Inc.) and boiled for $5 \mathrm{~min}$. Finally, the products were collected for western blotting.

Overexpression and knockdown of ITCH in HLECs. ITCH full-length cDNA was amplified from HLECs and ligated to a pEGFP-C1 vector (Thermo Fisher Scientific, Inc.) with the restriction sites of $\mathrm{SAC1}$ and BamH1. For overexpression of ITCH, pEGFP-C1-ITCH or empty vector [negative control (NC)] was mixed with Lipofectamine ${ }^{\circledR} 3000$ (Invitrogen; Thermo Fisher Scientific, Inc.) in serum-free DMEM for $5 \mathrm{~min}$. The mixtures were then added into each well in 6-well plates $\left(1 \times 10^{6}\right.$ cells) and incubated for $48 \mathrm{~h}$ at $37^{\circ} \mathrm{C}$ with $50 \mathrm{mM}$ glucose, before the cells were harvested for subsequent experiments. For knockdown of ITCH, small interfering (si)RNA or siNC (Guangzhou RiboBio Co., Ltd.) was mixed with
RiboFECT ${ }^{\mathrm{Tm}}$ CP Reagent (Guangzhou RiboBio Co., Ltd.) and RiboFECT ${ }^{\mathrm{TM}}$ CP Buffer (Guangzhou RiboBio Co., Ltd.) in serum-free DMEM medium for $15 \mathrm{~min}$. The mixtures were added into each well in 6-well plates $\left(1 \times 10^{6}\right.$ cells $)$ and incubated for $48 \mathrm{~h}$ at $37^{\circ} \mathrm{C}$ with $50 \mathrm{mM}$ glucose, and then subsequent experiments were conducted.

The following primers were designed and synthesized to detect ITCH full-length cDNA. ITCH forward, 5'-CGAGCT CAAATGTCTGACAGTGGATCACAA-3' and reverse, 5'-CGC GGATCCTTACTCTTGTCCAAATCCTTCTGTTTC-3'. PCR was performed under the following conditions: Initial denaturation at $98^{\circ} \mathrm{C}$ for $5 \mathrm{~min}$, followed by 35 cycles at $98^{\circ} \mathrm{C}$ for $10 \mathrm{sec}$, $55^{\circ} \mathrm{C}$ for $15 \mathrm{sec}, 68^{\circ} \mathrm{C}$ for $1 \mathrm{~min}$ and $68^{\circ} \mathrm{C}$ for $10 \mathrm{~min}$.

siRNA sequences were as follows: si-ITCH_01: GGAGCA ACATCTGGATTAA; si-ITCH_02: CAGCAATGGCAGAGT ATAT; and si-ITCH_03: GAGAAGAAGGTTTAGATTA.

MG132 treatment for cells. A specific ubiquitination inhibitor MG132 (Sangon Biotech Co., Ltd.) (23) $10 \mu \mathrm{M}$ was added to cells that had been transfected with pEGFP-C1-ITCH after incubation for $44 \mathrm{~h}$.

Cell proliferation assay by cell counting Kit-8 (CCK-8). Cell suspension was counted and inoculated in 96-well plates with $5 \times 10^{3}$ cells per well. Cells were adherent to the wall and cultured for $48 \mathrm{~h}$ in groups according to the following: $\mathrm{LG}$, HG1, HG2, HG3, siNC, siRNA-ITCH, pEGFP-C1-ITCH, pEGFP-C1 empty vector and MG132-pEGFP-C1-ITCH. The glucose concentration of each transfected group was $50 \mathrm{mM}$. Each group was divided into five multiple wells and a blank control group (only the culture medium without cells) was set up. $48 \mathrm{~h}$ after transfection, the new DMEM was replaced and $10 \mu \mathrm{l}$ of CCK-8 reagent (Beyotime Institute of Biotechnology) was added for a further culture for $1 \mathrm{~h}$. Then, $450 \mathrm{~nm}$ absorbance was detected by the automatic microplate reader (ELX-800, BioTek Instruments, Inc.).

Intracellular superoxide assay. Cells were plated in 96-well plates at $5 \times 10^{3}$ cells per well, cultured and grouped as mentioned for the CCK-8 assay, and were incubated with $200 \mu \mathrm{l}$ of the superoxide-detecting reagents, including WST-1 and catalase (Beyotime Institute of Biotechnology) at $37^{\circ} \mathrm{C}$ for $3 \mathrm{~min}$. An automatic microplate reader (ELX-800; BioTek Instruments, Inc.) was used to detect absorbance in $450 \mathrm{~nm}$.

Insulin disulfide reduction experiment for Trx activity assay. Trx activity was evaluated with insulin disulfide reduction assay, as previously reported $(24,25)$. NP40 protein lysis with PMSF (Beyotime Institute of Biotechnology) was added to the cells to extract the total protein. Lysate was incubated with $2 \mu \mathrm{l}$ DTT active buffer composed of $50 \mathrm{mM}$ HEPES (pH 7.6), $1 \mathrm{mM}$ EDTA, $1 \mathrm{mg} / \mathrm{ml}$ BSA and $2 \mathrm{mM}$ DTT solution (Beyotime Institute of Biotechnology) at $37^{\circ} \mathrm{C}$ for $20 \mathrm{~min}$. Then, the reaction buffer containing $200 \mu \mathrm{l} 1 \mathrm{M}$ HEPES (pH 7.6), $40 \mu 1$ 0.2 M EDTA, $40 \mu 140$ mg/ml NADPH (Beyotime Institute of Biotechnology) and $500 \mu 110 \mathrm{mg} / \mathrm{ml}$ insulin (Beyotime Institute of Biotechnology) was added. The reaction was started by the addition of $10 \mu \mathrm{l}$ recombinational Trx reductase (Abcam) and incubated for $20 \mathrm{~min}$ at $37^{\circ} \mathrm{C}$. The reaction was terminated by the addition $0.5 \mathrm{ml} 6 \mathrm{~mol} / \mathrm{l}$ 
A

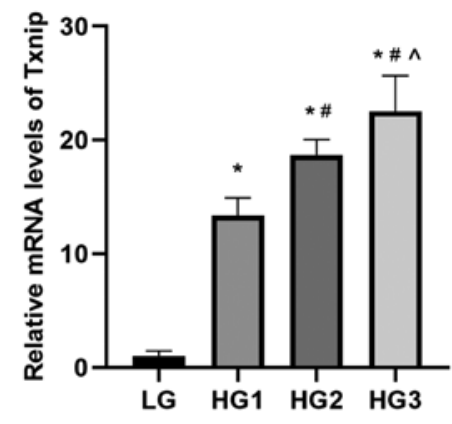

C

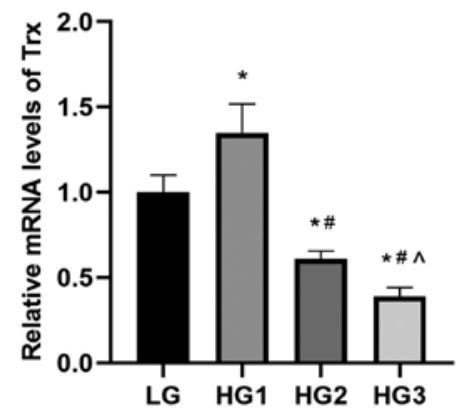

E

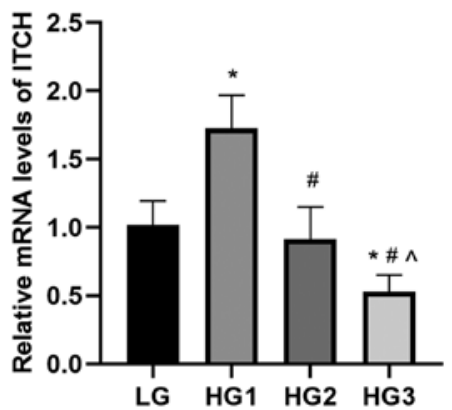

B

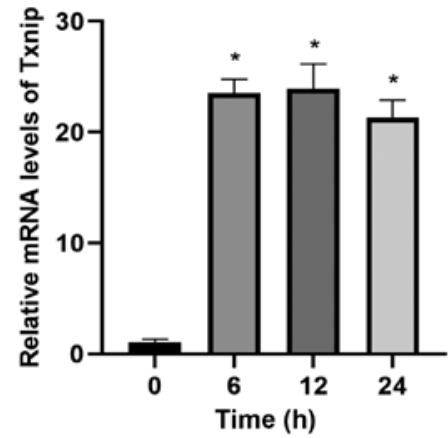

D

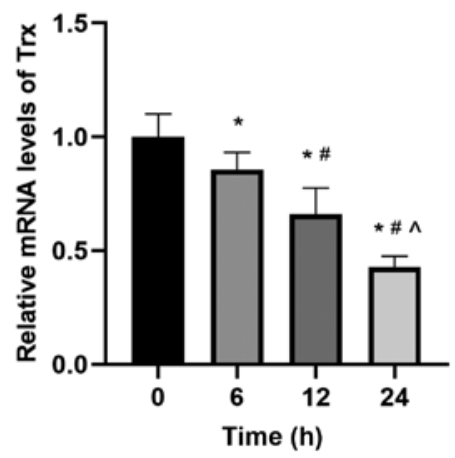

F

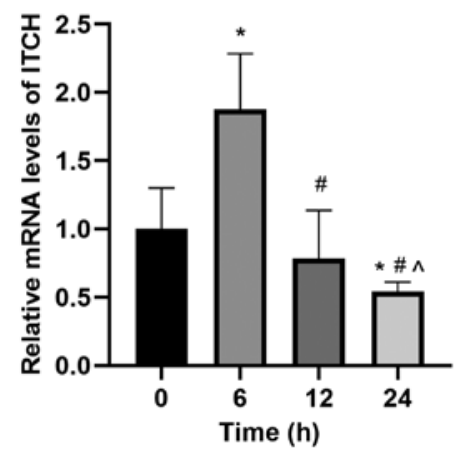

Figure 1. mRNA expression levels of Txnip, Trx and ITCH in HLECs. HLECs were treated with different concentration of glucose (LG, 5.5 mM; HG1, $12.5 \mathrm{mM}$; HG2, $25 \mathrm{mM}$; HG3, $50 \mathrm{mM}$ ) for $24 \mathrm{~h}$ or treated with $50 \mathrm{mM}$ glucose for different incubation time (0,6, 12 and $24 \mathrm{~h}$ ). (A and B) Txnip. (C and D) Trx. (E and F) ITCH. Data are presented as the mean \pm standard deviation and analyzed by ANOVA followed by Tukey-Kramer multiple comparison post hoc tests. ${ }^{*} \mathrm{P}<0.05$ vs. LG or $0 \mathrm{~h} ;{ }^{\#} \mathrm{P}<0.05$ vs. HG1 or $6 \mathrm{~h} ;{ }^{\wedge} \mathrm{P}<0.05 \mathrm{vs}$. HG 2 or $12 \mathrm{~h}$. Txnip, thioredoxin interaction protein; Trx, thioredoxin; HLECs, human lens epithelial cells; LG, low glucose; HG, high glucose.

guanidine- $\mathrm{HCl}$ and $1 \mathrm{mmol}$ DTNB (Beyotime Institute of Biotechnology) and absorbance at $412 \mathrm{~nm}$ was measured using an automatic microplate reader (ELX-800; BioTek Instruments, Inc.).

Flow cytometry for cell apoptosis assay. Cells were cultured and treated for $48 \mathrm{~h}$ in the same condition as mentioned for the CCK-8 assay, and then the procedure was performed according manufacturer's instructions of the Annexin V-APC/7-AAD apoptosis kit (Wanleibio Co., Ltd.). Then, flow cytometry (Accuri C6; BD Biosciences) was used to determine the apoptotic rate of each group.

Statistical analysis. SPSS 24.0 statistical software (IBM Corp.) and GraphPad Prism 8.0 (GraphPad Software, Inc.) were used for data statistics and analysis. One-way ANOVA followed by Tukey-Kramer multiple comparison post hoc tests was used for multiple groups. $\mathrm{P}<0.05$ was considered to indicate a statistically significant difference.

\section{Results}

Expression levels of Txnip, Trx and ITCH were affected by high glucose in HLECs. It was found that the mRNA and protein expression levels of Txnip in HLECs were increased in a time-dependent and concentration-dependent manner after glucose stimulation ( $\mathrm{P}<0.05$; Figs. $1 \mathrm{~A}$ and $\mathrm{B}$ and $2 \mathrm{~A}$ and $\mathrm{B}$ ). However, the trends of Trx and ITCH showed an opposite effect to Txnip ( $\mathrm{P}<0.05$; Figs. $1 \mathrm{C}-\mathrm{F}$ and $2 \mathrm{C}-\mathrm{F})$. The mRNA expression levels of Txnip, Trx and ITCH showed no significant difference between LG and mannitol groups (Fig. S1A-C). The insulin disulfide reduction assay results indicated that the activity of Trx protein in the LG group was the highest, which gradually decreased with the increase in glucose concentration 
A
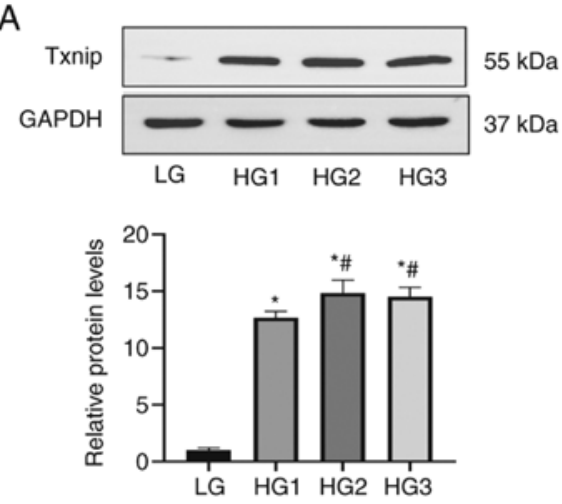

C
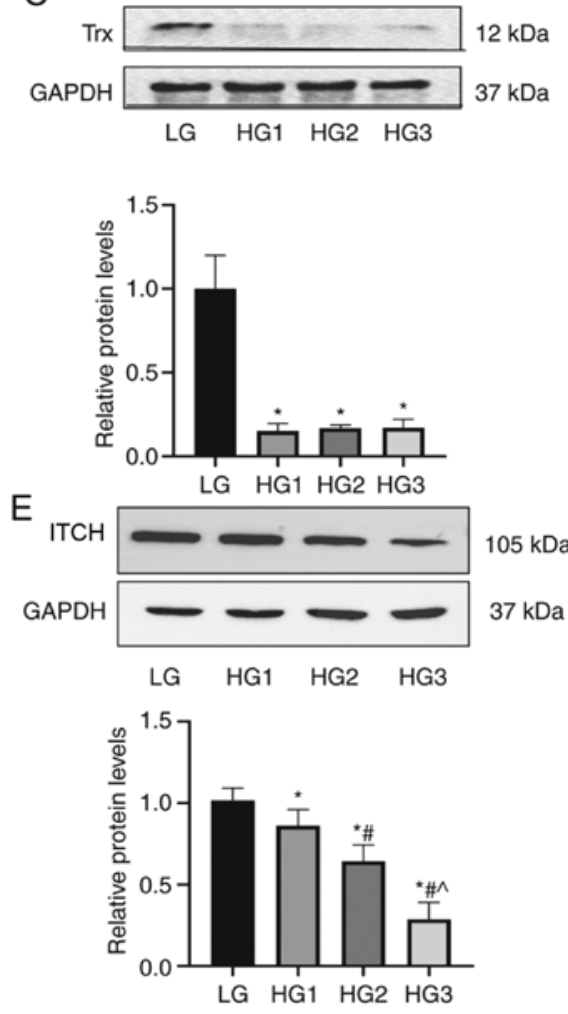

B
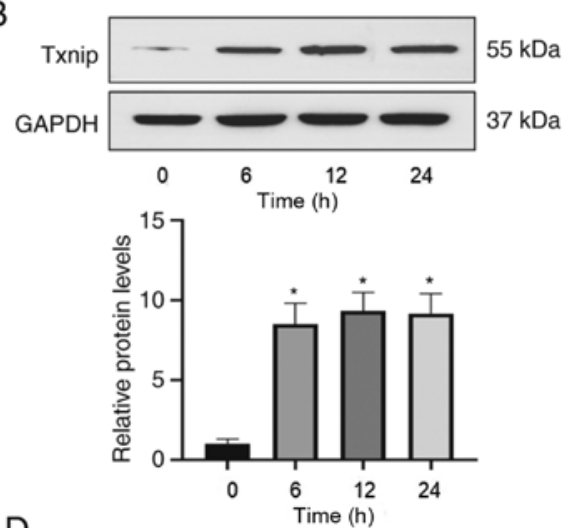

D
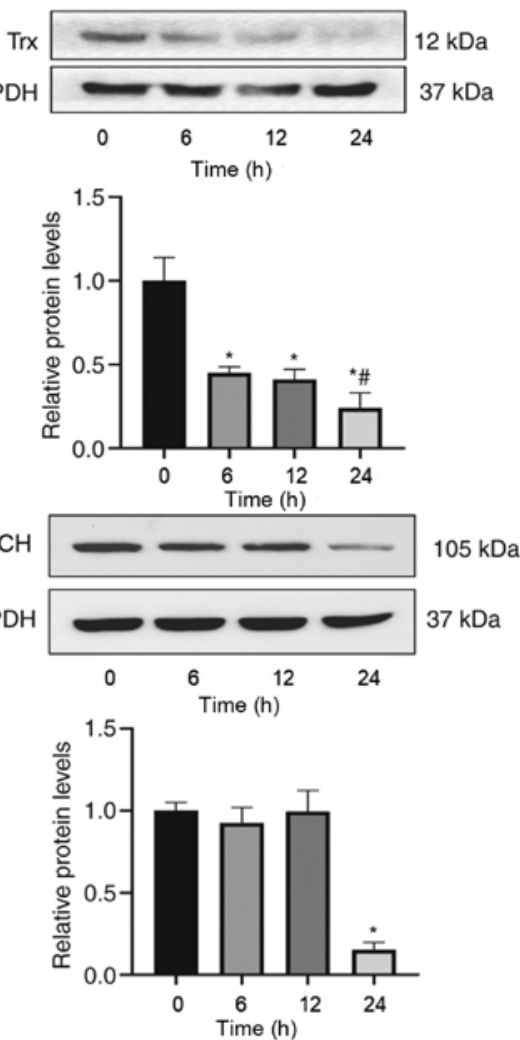

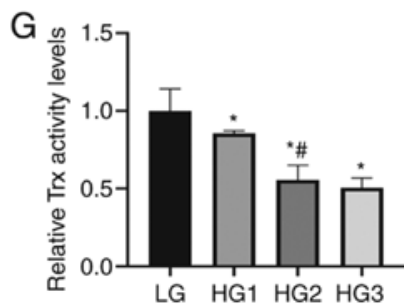

Figure 2. Protein expression levels of Txnip, Trx and ITCH in HLECs. HLECs were treated with different glucose concentration (LG, 5.5 mM; HG1, 12.5 mM; HG2, $25 \mathrm{mM}$; HG3, $50 \mathrm{mM}$ ) for $24 \mathrm{~h}$ or treated with $50 \mathrm{mM}$ glucose for different incubation time (0, 6, 12 and $24 \mathrm{~h}$ ). (A and B) Txnip. (C and D) Trx. (E and F) ITCH. (G) Activity levels of Trx protein via insulin disulfide reduction experiment in different groups. Data are presented as the mean \pm standard deviation and analyzed by ANOVA followed by Tukey-Kramer multiple comparison post hoc tests. " $\mathrm{P}<0.05$ vs. LG or 0 h; ${ }^{\#} \mathrm{P}<0.05$ vs. HG1 or $6 \mathrm{~h}$; ${ }^{\wedge} \mathrm{P}<0.05$ vs. HG2 or $12 \mathrm{~h}$. Txnip, thioredoxin interaction protein; Trx, thioredoxin; HLECs, human lens epithelial cells; LG, low glucose; HG, high glucose.

(P<0.05; Fig. 2G). Using immunofluorescence localization, it was demonstrated that the expression localization of Trx protein in LG group was in nucleus and cytoplasm, and the main expression location was in the nucleus (Fig. 3A-C). In the HG3 group, with the increase of glucose concentration, the expression of Trx was transferred from the nucleus to the cytoplasm, and the main expression was located in the cytoplasm (Fig. 3D-F).
Cell proliferation, intracellular superoxide accumulation and apoptosis were affected by high glucose in HLECs. The CCK-8 results suggested that the proliferation rate of cells showed a significant increase with rising glucose concentration $(\mathrm{P}<0.05)$, while the $25-\mathrm{mM}$ concentration (HG2 group) was an inflection point. Subsequently, with the continuing increase in concentration of glucose, proliferation was decreased (HG3 group; $\mathrm{P}<0.05 ;$ Fig. 4A). The intracellular superoxide detection assay 

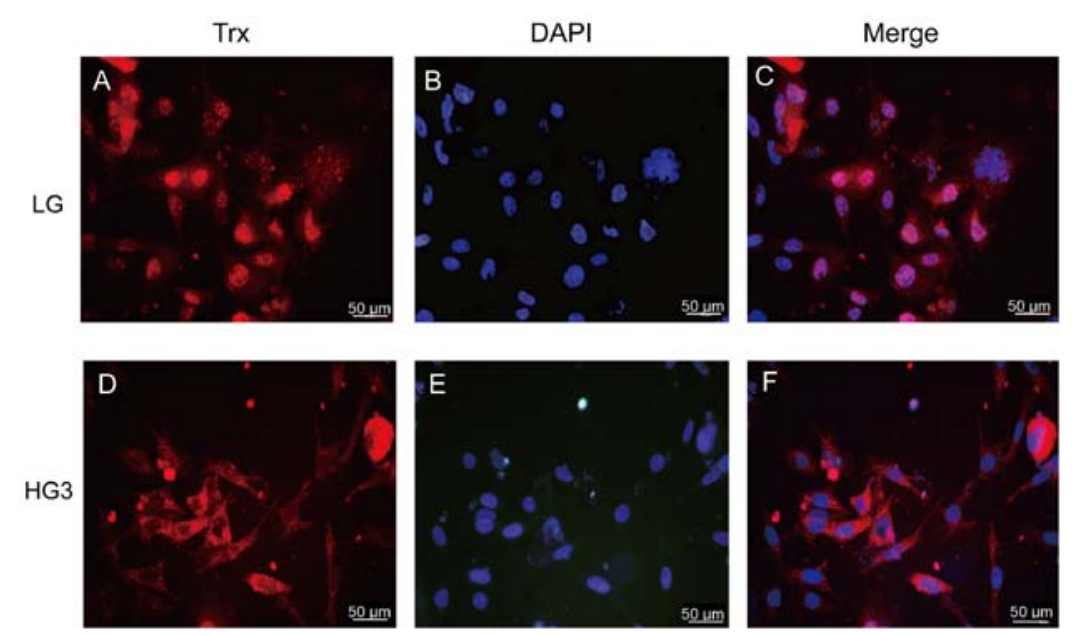

Figure 3. Trx localization in HLECs in LG and HG3. (A-C) Localization of Trx protein in LG group was found to be in the nucleus and cytoplasm, mainly in the nucleus. (D-F) In the HG3 group, the localization of Trx was transferred from the nucleus to the cytoplasm, and the main expression was located in the cytoplasm. Txnip, thioredoxin interaction protein; Trx, thioredoxin; HLECs, human lens epithelial cells; LG, low glucose; HG, high glucose.

results identified an increase of superoxide in the HG1 group compared with the LG group, and this continued to increase with the elevated glucose concentration $(\mathrm{P}<0.05$; Fig. 4B).

For cell apoptosis, the content of the classical apoptotic protein caspase-3 in each group was detected by western blotting, and it was found that compared with the LG group, caspase-3 expression gradually decreased in HG1, HG2 and HG3 groups $(\mathrm{P}<0.05$; Fig. 4C). Furthermore, flow cytometry was used to quantitatively determine the apoptotic rate of each group of cells, which demonstrated the same trend as western blotting $(\mathrm{P}<0.05$; Fig. 4D).

Interaction between ITCH and Txnip, Txnip and Trx. Immunofluorescence co-localization reflected that Txnip and ITCH proteins were expressed in both the nucleus and cytoplasm of HLECs cultured with $50 \mathrm{mM}$ glucose (Fig. 5A). Subsequently, Image Pro Plus 6.0 was used for co-location analysis of these two proteins and the results were as follow: Pearson's correlation, $r=0.953276$, suggested a strong correlation between the two proteins in HLECs (Fig. 5B). For the HG3 group, COIP analysis indicated a prominent band expression of ITCH at $105 \mathrm{kDa}$ after IP Txnip (rabbit monoclonal antibody) and adding ITCH antibody (rabbit monoclonal antibody) (Fig. 5C). Furthermore, Txnip antibody (mouse monoclonal antibody) was added and a significant band of Txnip expression was observed at $55 \mathrm{kDa}$. After IP with ITCH (rabbit monoclonal antibody), Txnip antibody (mouse monoclonal antibody) was added and the expression of Txnip protein band was identified at $55 \mathrm{kDa}$ (Fig. 5C). In addition, ITCH antibody of rabbit origin was also added, and there was a significant ITCH protein band expression at $105 \mathrm{kDa}$ (Fig. 5C). For the LG group, COIP analysis indicated that after IP Txnip, there was no prominent ITCH band at $105 \mathrm{kDa}$ and after IP ITCH, the Txnip band was barely visible at $55 \mathrm{kDa}$ (Fig. 5D). For the HG3 group, COIP analysis also demonstrated that after IP Txnip (rabbit monoclonal antibody), and Trx antibody (rabbit monoclonal antibody) was added, a prominent band of Trx at $12 \mathrm{kDa}$ was shown (Fig. 5E). After IP Trx (rabbit monoclonal antibody), and Txnip antibody (mouse monoclonal antibody) was added, the expression of Txnip protein band at $55 \mathrm{kDa}$ was observed (Fig. 5E).
Transfection of pEGFP-C1-ITCH plasmid and siRNA-ITCH causes changes in the expression of associated proteins in high-glucose environment. Compared with the HG3 group, ITCH protein overexpression after transfection of pEGFP-C1-ITCH led to a series of changes in the downstream proteins: After the increase in ITCH expression, Txnip was significantly degraded, while Trx expression was increased $(\mathrm{P}<0.05$; Fig. 6A). In addition, caspase-3 expression was increased $(\mathrm{P}<0.05$; Fig. $6 \mathrm{~A})$. However, the relative expression of each protein in the cells transfected with empty plasmid was not statistically different compared with the HG3 group $(\mathrm{P}<0.05$; Fig. 6A). When MG132 was added to the transfection group, Txnip expression was increased, which reversed the trend of the overexpression of ITCH $(\mathrm{P}<0.05$; Fig. 6A). Compared with the HG3 group, ITCH expression was significantly decreased following the knockdown of ITCH mRNA, while the expression of downstream proteins Txnip, Trx and caspase-3 proteins demonstrated an opposite trend compared with the pEGFP-C1-ITCH group $(\mathrm{P}<0.05$; Fig. 6B). The activity of Trx in different groups were detected under high-glucose concentration $(50 \mathrm{mM})$ by the insulin disulfide reduction experiment. Trx activity was highest in pEGFP-C1-ITCH group, while MG132 reversed the increase and caused a decrease in $\operatorname{Tr} x$ activity $(\mathrm{P}<0.05)$; whilst $\operatorname{Tr} x$ activity was significantly decreased in the siRNA-ITCH group $(\mathrm{P}<0.05$; Fig. 6C).

Effects of overexpression and knockdown of ITCH on cell proliferation, superoxide content and apoptosis in high-glucose environment. The CCK-8 results indicated that the cell proliferation in the pEGFP-C1-ITCH group was higher compared with the HG3 group, but this trend was reversed by MG132 and the proliferation rate decreased $(\mathrm{P}<0.05)$. Furthermore, the proliferation rate of the siRNA-ITCH group was lower compared with the HG3 group ( $\mathrm{P}<0.05$; Fig. 7A).

With regards to the detection of intracellular superoxide, it was found that the content of superoxide in the pEGFP-C1-ITCH group was lower compared with the HG3 group, but increased significantly after MG132 treatment $(\mathrm{P}<0.05)$; the superoxide content of the siRNA-ITCH group was also higher compared 
A

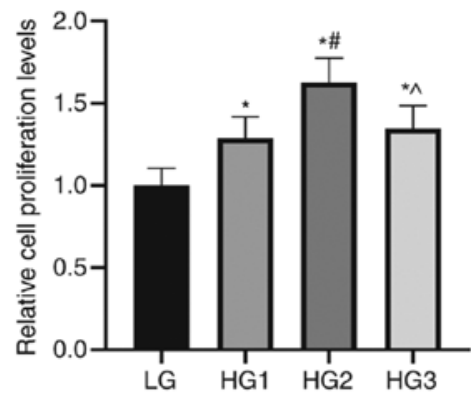

C

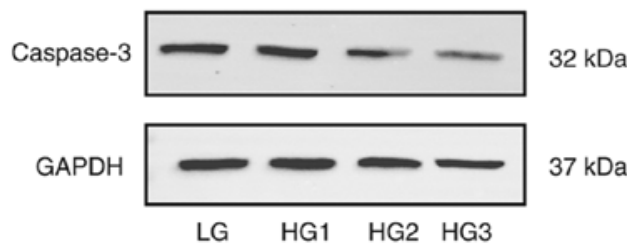

B
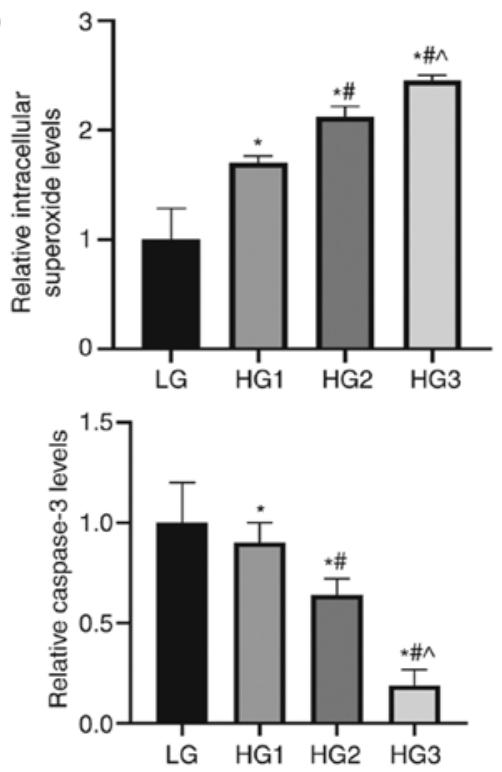
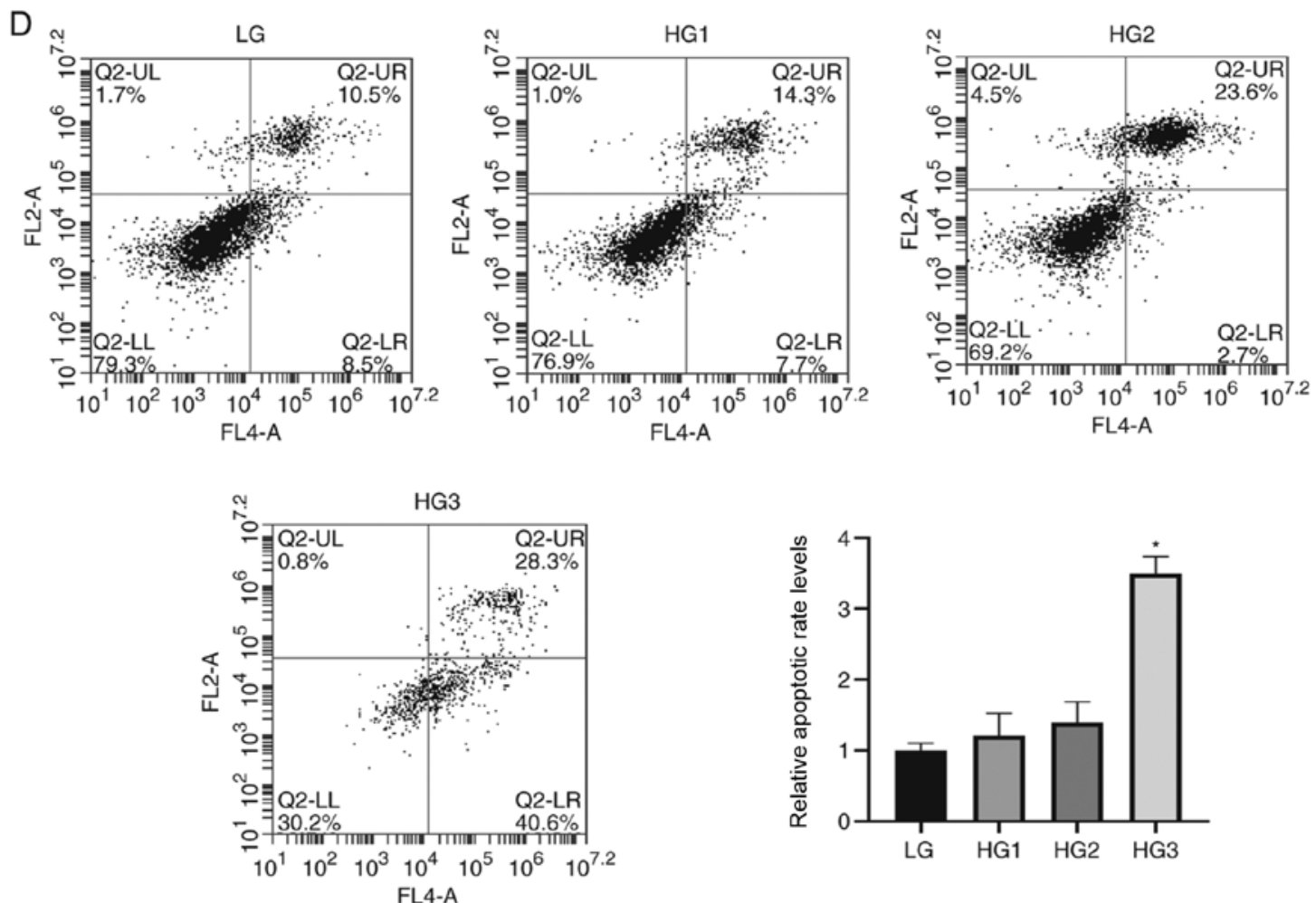

Figure 4. Cell proliferation, intracellular superoxide accumulation and apoptosis are affected by high glucose in HLECs. (A) Cell proliferation levels of HLECs that were treated with different glucose concentrations (LG, $5.5 \mathrm{mM}$; HG1, $12.5 \mathrm{mM} ; \mathrm{HG} 2,25 \mathrm{mM}$; HG3, $50 \mathrm{mM}$ ) for $48 \mathrm{~h}$ were analyzed via Cell Counting Kit-8. (B) Intracellular superoxide levels of HLECs in each group. (C) Protein expression levels of caspase-3 measured via western blotting. (D) Cell apoptotic rate of each group assessed via flow cytometry. Data are presented as the mean \pm standard deviation and analyzed by ANOVA followed by Tukey-Kramer multiple comparison post hoc tests. ${ }^{*} \mathrm{P}<0.05$ vs. LG; ${ }^{\mathrm{P}} \mathrm{P}<0.05$ vs. HG1; ${ }^{\wedge} \mathrm{P}<0.05$ vs. HG2. HLECs, human lens epithelial cells; LG, low glucose; HG, high glucose.

with the HG3 group (P<0.05; Fig. 7B). The flow cytometry assay demonstrated that the apoptotic rate of the cells were consistent with the results of the superoxide content $(\mathrm{P}<0.05$; Fig. 7C and D).

\section{Discussion}

To the best of our knowledge, the present study was the first to demonstrate the association between oxidative stress and Trx and Txnip in HLECs cultured in a high-glucose-induced oxidative stress status. Cataract is the most common eye disease causing blindness worldwide (1), and its occurrence is associated with numerous factors, among which oxidative stress is an important pathway (26). In addition, as a disease associated with oxidative stress, diabetes accelerates and aggravates the development and progression of cataract (27).

Trx is an important protein that widely exists in eukaryotic cells to protect against oxidative stress. Trx has a stable and unique catalytic group-cys-gly-pro-cys and through this group, Trx in a reduced state can provide $\mathrm{H}^{+}$for other proteins 

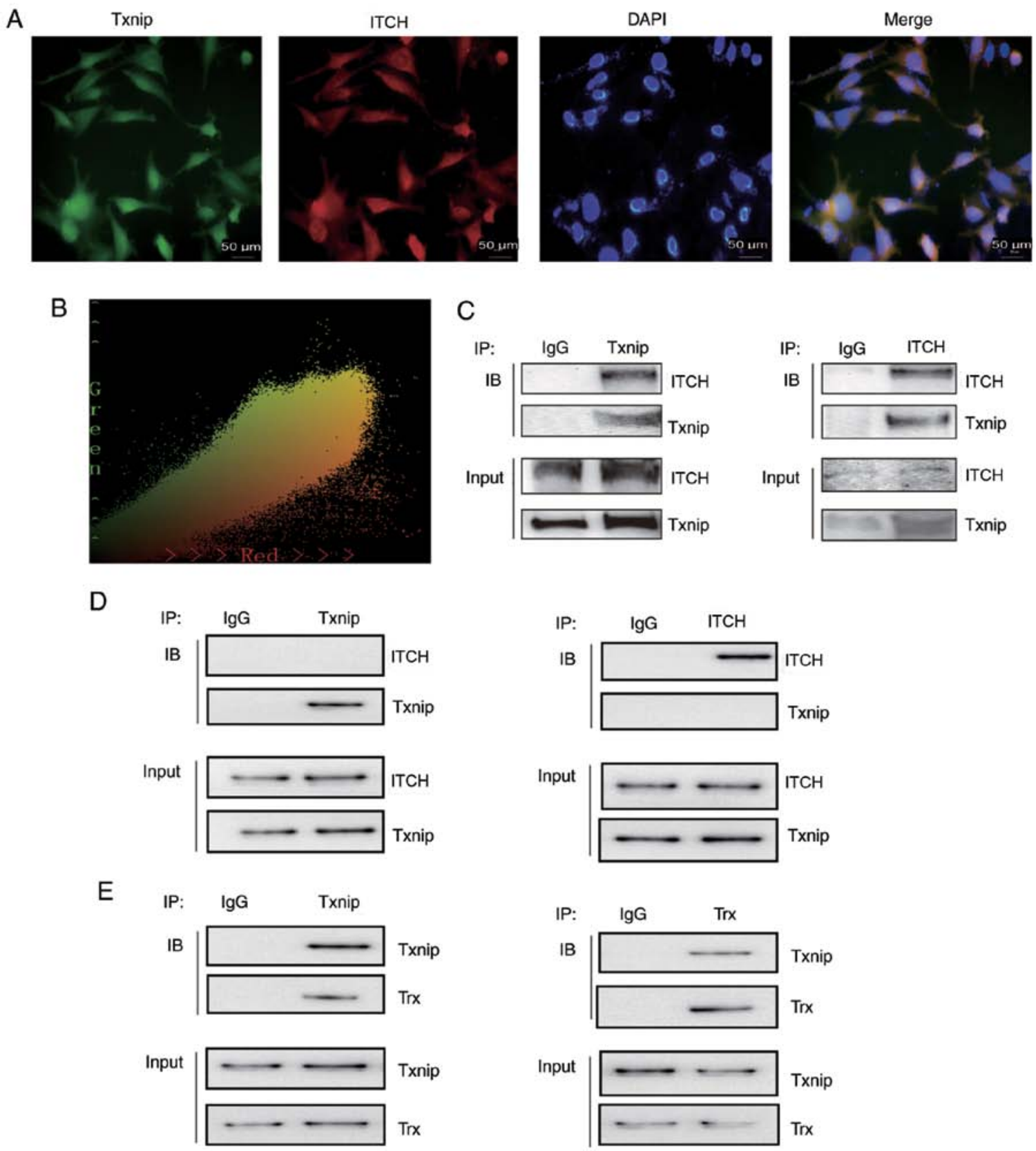

Figure 5. Interaction between ITCH and Txnip, Txnip and Trx. (A) Txnip and ITCH proteins were detected by immunofluorescence co-localization experiment in HLECs, which were cultured in $50 \mathrm{mM}$ glucose. (B) Co-location analysis of the Txnip and ITCH proteins by Image Pro Plus 6.0. Pearson's correlation, $\mathrm{r}=0.953276$. Horizontal axis, ITCH; vertical axis, Txnip. (C) Co-immunoprecipitation showed that Txnip bound with ITCH in HLECs that were cultured in $50 \mathrm{mM}$ glucose. (D) Co-immunoprecipitation showed that Txnip barely bound with ITCH in HLECs that were cultured in $5.5 \mathrm{mM}$ glucose. (E) Co-immunoprecipitation showed that Txnip bound with Trx in HLECs that were cultured in $50 \mathrm{mM}$ glucose. Txnip, thioredoxin interaction protein; Trx, thioredoxin; HLECs, human lens epithelial cells.

containing disulfide bonds, which reduces the oxidation of the target protein (28). Txnip was originally identified as a protein that induces high levels of vitamin D3 expression in human HL-60 cells, and hence was named VDUP1 (29). Txnip is synthesized in large quantities in a high-glucose environment, and strongly binds cysteine residues to the reduce Trx via a disulfide exchange reaction, resulting in Trx losing its ability to resist oxidative stress (11). The present study quantitatively analyzed the changes in the expression levels of Txnip and Trx in culture environments with different glucose concentrations at different durations of action. It was demonstrated that with the increase in glucose concentration in the medium and the extension of the time of action, the expression of Txnip was increased, while Trx decreased. Although the mRNA expression of Trx in the HG1 group increased, it was speculated that it was an adaption to the rise in high glucose concentration in the early stage of oxidative stress. In line with previous studies, the present results suggested that Txnip and Trx were closely associated with glucose concentration in HLECs cultured in vitro, and showed an opposite trend, thus indicating that they may have antagonistic effects. The mRNA expression levels of Txnip, Trx and ITCH showed no significant difference between LG and mannitol groups, which suggested that the changes should not be caused by osmotic pressure. Spielberger's study (30) showed that 
A
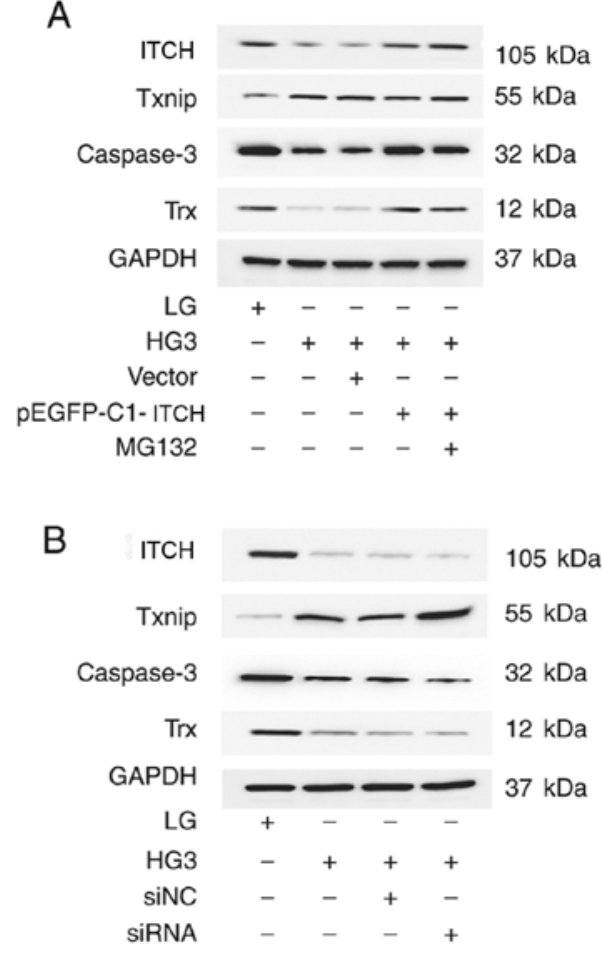
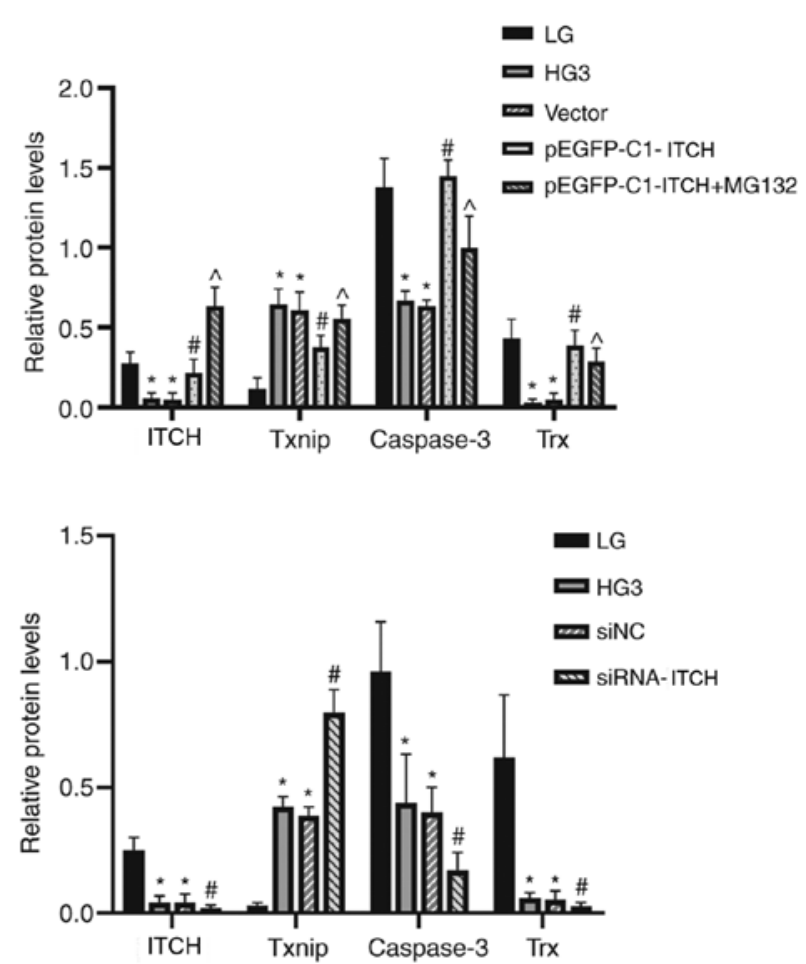
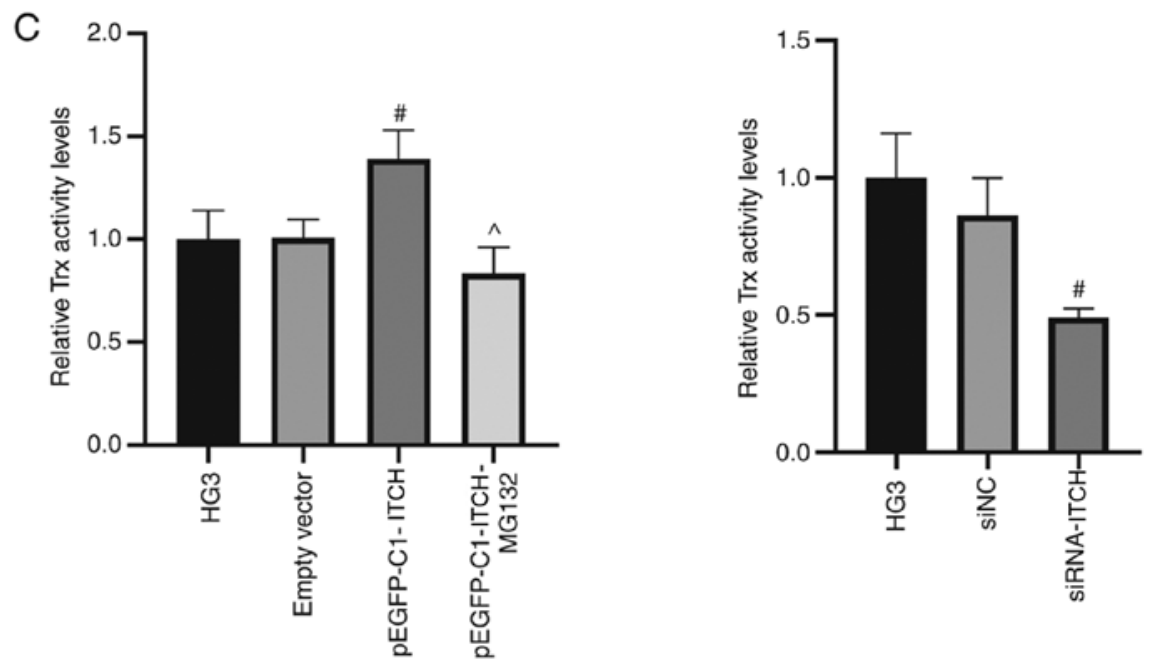

Figure 6. Overexpression and knockdown of ITCH in HLECs and the changes in the downstream proteins. (A) Transfection of pEGFP-C1-ITCH plasmid and MG132 treatment showed changes in the expression of associated proteins: ITCH, Txnip, Trx and caspase-3 via western blotting in low- and high-glucose environment. (B) Transfection of siRNA-ITCH revealed changes in the expression of associated proteins in low- and high-glucose environment via western blotting. (C) Change in Trx activity in the pEGFP-C1-ITCH-, MG132-treated and siRNA-ITCH group in high-glucose environment via insulin disulfide reduction experiment. Data are presented as the mean \pm standard deviation and analyzed by ANOVA followed by Tukey-Kramer multiple comparison post hoc tests. ${ }^{*} \mathrm{P}<0.05$ vs. $\mathrm{LG}$; ${ }^{*} \mathrm{P}<0.05$ vs. HG3; ${ }^{\wedge} \mathrm{P}<0.05$ vs. pEGFP-C1-ITCH. Txnip, thioredoxin interaction protein; Trx, thioredoxin; HLECs, human lens epithelial cells; siRNA-ITCH, small interfering RNA-ITCH; NC, negative control.

the expression of $\operatorname{Tr} 1$ was also correlated with the cell density: The amount of Trx1 was greater in sparse (low density; $20 \%$ confluent) cultures compared with confluent (high density; $95 \%$ confluent) cultures in HeLa cells, A549 cells and 293 cells. In human lens epithelial cells, it was unknown whether cell density affected the expression of Trx1. Therefore, the same initial cell density (70\% confluence) was used in order to measured $\operatorname{Tr} x$ expression between cultures with similar cell density, to avoid the deviation by the effect of cell proliferation. The present results suggested that the changes in Txnip expression induced by glucose affected Trx expression.
Immunofluorescence experiments demonstrated that Trx was located both in nucleus and cytoplasm in the LG group, mainly with nuclear expression. However, in the HG3 group, its expression was transferred from the nucleus to the cytoplasm, and thus it was speculated that Trx was transferred to mitochondria, the main site of oxidative stress response, to play its role. The insulin disulfide reduction experiment also identified that the activity of Trx was decreased in the high-glucose environment.

The CCK- 8 results indicated that with the increased concentration of glucose, cell proliferation rate at first 
A

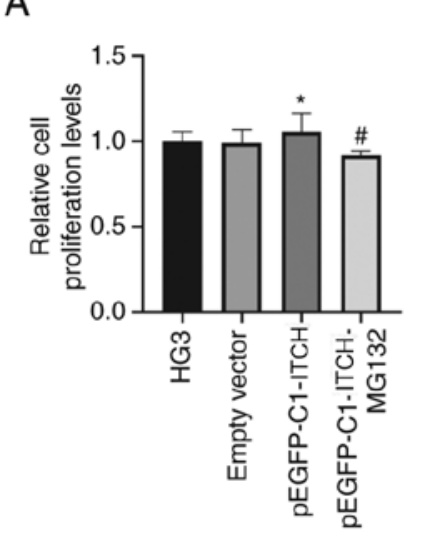

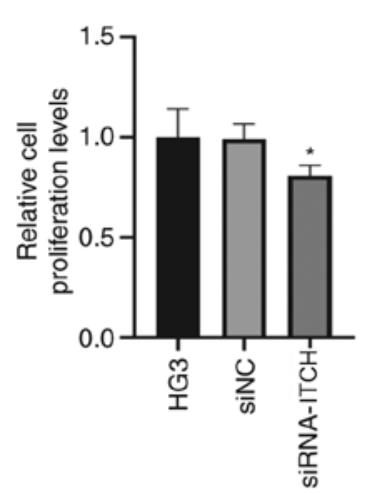

B

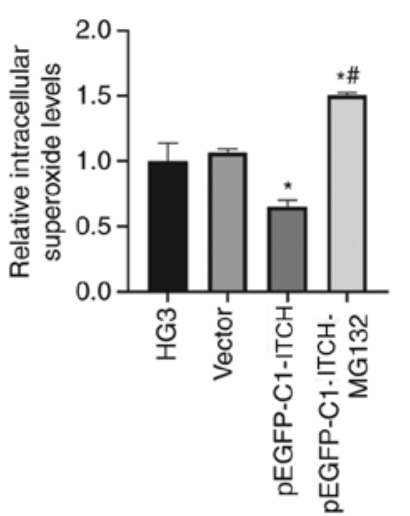

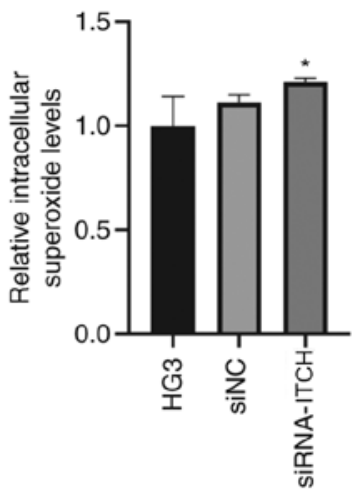
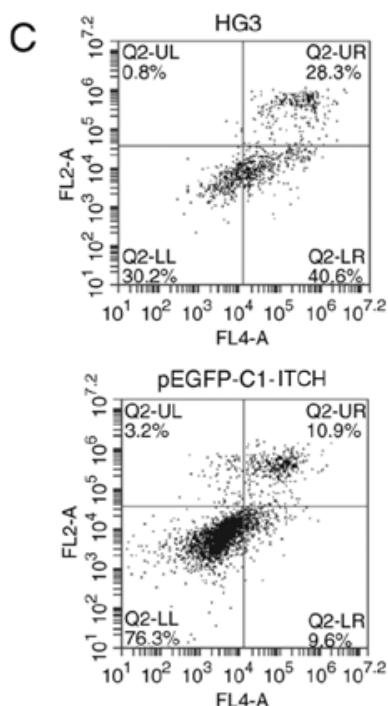
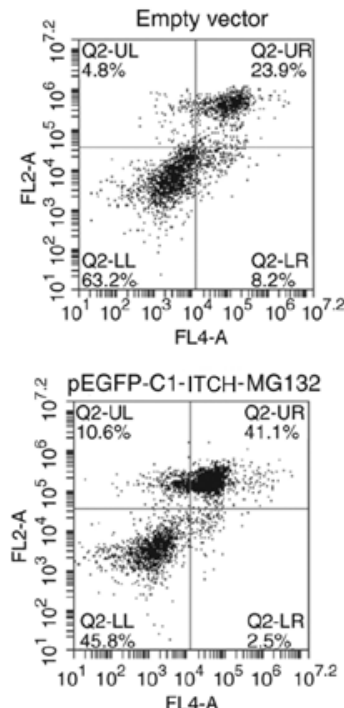
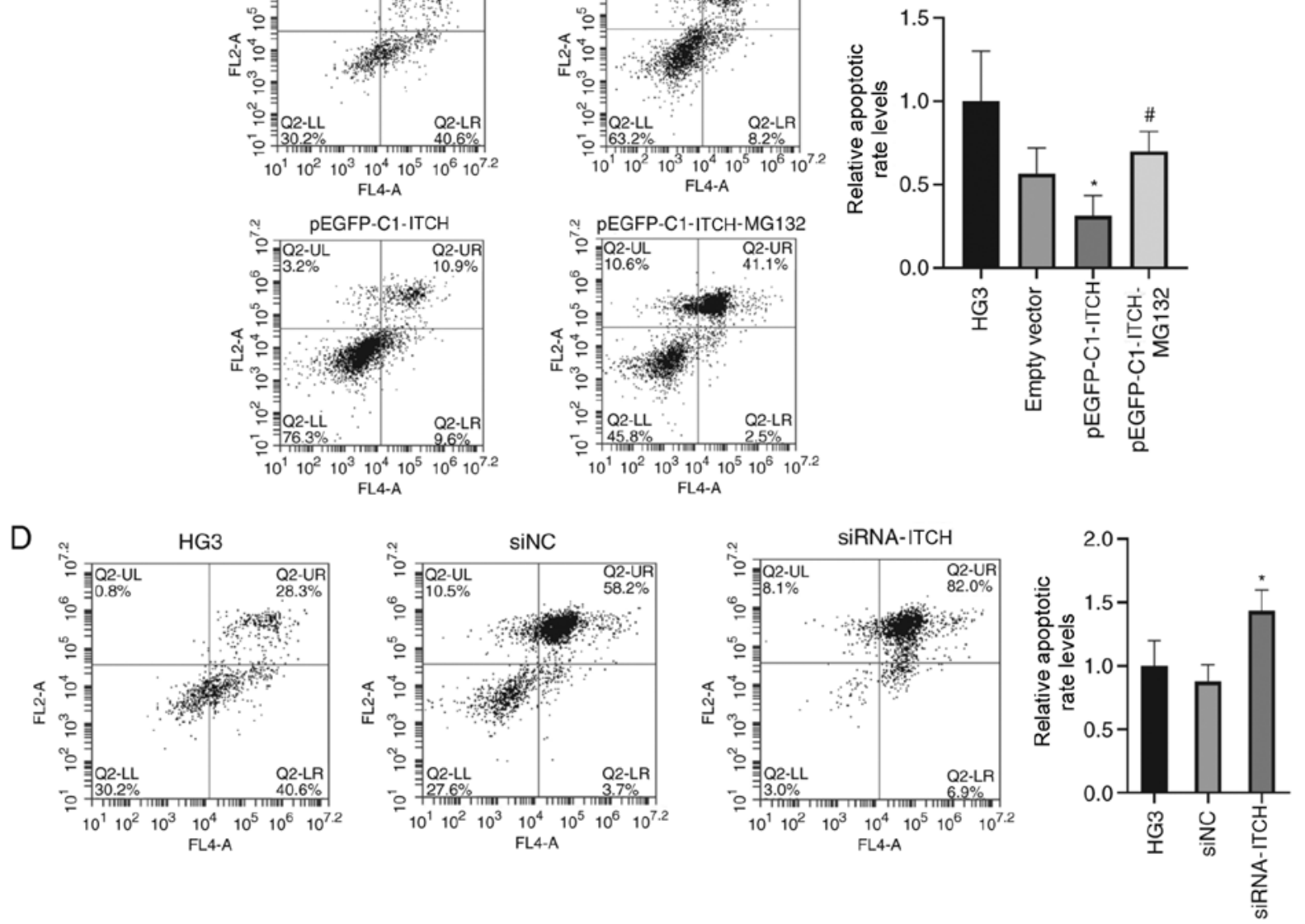

Figure 7. Overexpression and knockdown of ITCH in HLECs altered the cell proliferation and intracellular superoxide content in high-glucose environment. (A) Change in cell proliferation in pEGFP-C1-ITCH-, MG132-treated and siRNA-ITCH group in high-glucose environment shown by the Cell Counting Kit-8 experiment. (B) Variation in intracellular peroxide content in the aforementioned groups. (C and D) Apoptotic rate of cells were detected by flow cytometry. Data are presented as the mean \pm standard deviation and analyzed by ANOVA followed by Tukey-Kramer multiple comparison post hoc tests. "P<0.05 vs. HG3; ${ }^{\text {"P}}$ <0.05 vs. pEGFP-C1-ITCH. HLECs, human lens epithelial cells; siRNA-ITCH, small interfering RNA-ITCH; NC, negative control.

increased, but then began to decrease at the inflection point at $25 \mathrm{mM}$ glucose. Therefore, it was suggested that this may be a response caused by overnutrition before $25 \mathrm{mM}$ glucose. Moreover, the results demonstrated that superoxide content was closely associated with glucose. It has been reported that Txnip protein induces apoptosis via several pathways, including the classical caspase pathway, the MAPK pathway and the NLR family pyrin domain containing 3 pathway $(31,32)$. Therefore, the present study examined the caspase- 3 protein expression in the caspase pathway and found that with the increase in glucose concentration, the expression of caspase-3 was gradually decreased. Subsequently, flow cytometry experiments further indicated that with the gradual increase in glucose, the apoptotic rate of cells showed an increasing trend.

Ubiquitination is a reversible covalent modification and a multistage enzyme-linked reaction process, which is completed via the continuous action of ubiquitin-activated enzyme E1, ubiquitin-conjugating enzyme E2 and ubiquitin ligase E3 (18). ITCH, as one of the E3 ligases in the HECT family, has been reported to be closely associated with several diseases, such as 


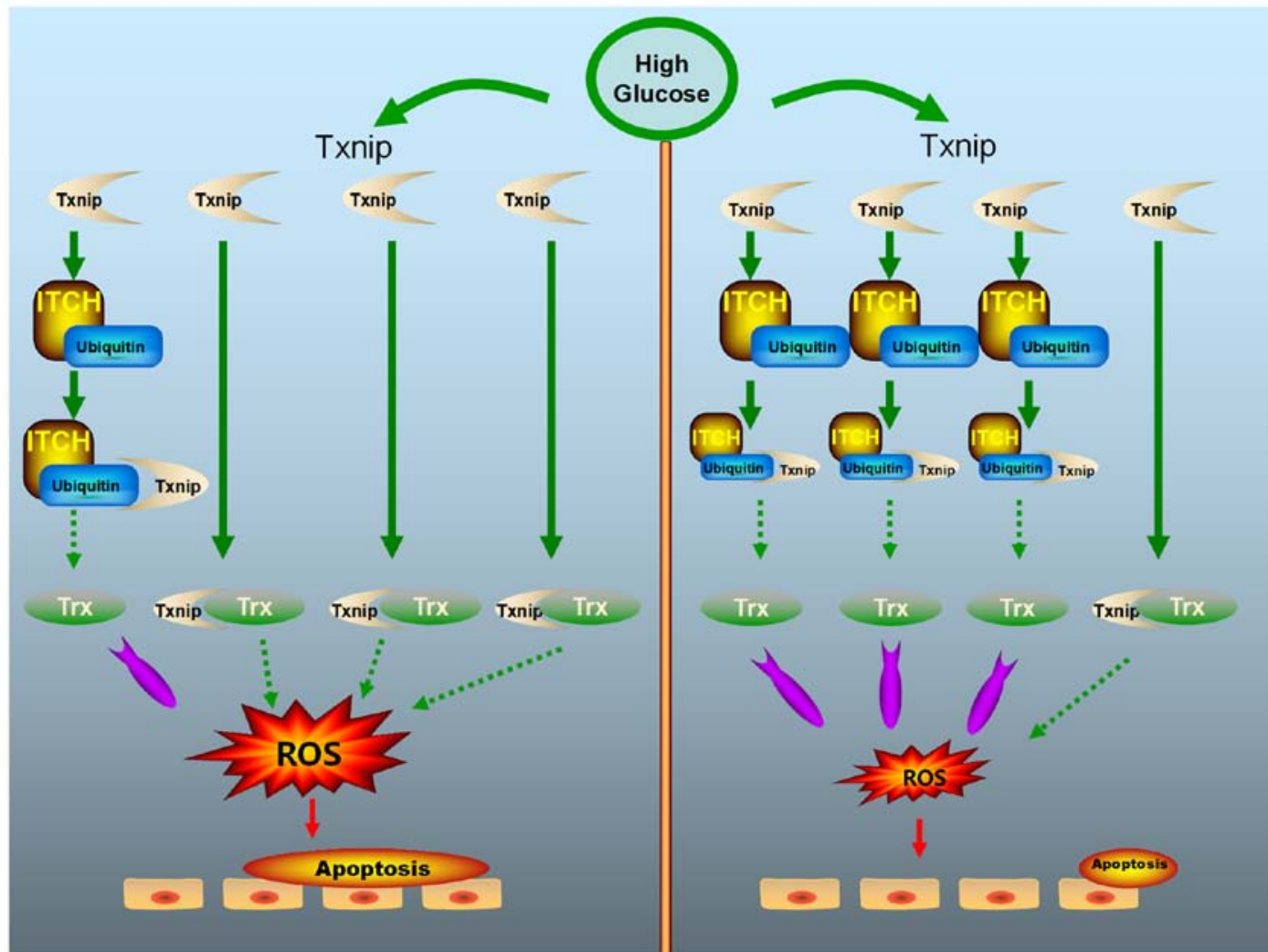

Figure 8. Schematics of the proposed pathway of ITCH in high glucose-induced apoptosis of HLECs. Left, normal HLECs. Right, ITCH-overexpressing HLECs. Txnip, thioredoxin-interacting protein; Trx, thioredoxin; ROS, reactive oxygen species.

autoimmune disease, chronic pulmonary disease, rheumatoid arthritis and allergic dermatitis, as well as abnormalities in the morphology of cranial and facial muscles (33). A previous study has shown that ITCH consumption can cause intracellular oxidative stress and induce apoptosis (34). However, its presence, mechanism and effect in ocular lens epithelial cells have not been previously reported. In the present study, ITCH mRNA and protein expression levels in HLECs were detected, and the changes in expression, which was similar to $\operatorname{Trx}$, was confirmed in the different groups. In line with previous studies, it was speculated that ITCH was associated with oxidative stress in HLECs. It has been reported that Txnip is the specific target protein of ITCH in 293T, H1299 and U2OS cells, which mediates the degradation of Txnip and regulates apoptosis (34). Therefore, in the present study, the co-location analysis at $50 \mathrm{mM}$ glucose concentration suggested a strong correlation between Txnip and ITCH. Moreover, the interaction between Txnip and ITCH in HLECs was assessed by co-localization of immunofluorescence and COIP in the HG3 group; it was demonstrated that the interaction between ITCH and Txnip was very weak at $5.5 \mathrm{mM}$ glucose concentrations compared with $50 \mathrm{mM}$. In addition, the interaction between Txnip and Trx was observed in HLECs in $50 \mathrm{mM}$ glucose concentration.

In the present study, ITCH was used to regulate the oxidative stress process caused by Txnip. ITCH was overexpressed by transfection, which downregulated Txnip and caused the release of active Trx, leading to the increase in proliferation rate, the decline in superoxide content and apoptotic rate in cells. To investigate whether the changes were caused by ubiquitination, MG132, a specific ubiquitination inhibitor, was added and it was found that MG132 completely reversed the changes in protein expression and cell function caused by the transfection. It was also demonstrated that MG132 mainly inhibited the binding of ubiquitin molecules to target proteins instead of degrading them. In the MG132 treatment group, it was identified that with the increase in ITCH expression, there was no reduction in Txnip. Moreover, the degradation of ITCH itself is dependent on the ubiquitin-proteasome proteolytic digestion system, and the specific protein identification of ITCH by ubiquitin E3 ligase is via ITCH itself (35). Therefore, MG132 inhibited ubiquitination and ITCH degradation at the same time, which lead to an increase in ITCH expression, while no decrease in Txnip expression, and this process also identified that the regulation of oxidative stress was accomplished via ubiquitination. Collectively, it was speculated that the ubiquitination of ITCH by transfection with ITCH overexpression plasmids reversed the oxidative stress of Txnip. Furthermore, the knockout of ITCH found that the downstream associated protein showed an opposite change in trend compared with the overexpression of ITCH.

In conclusion, the present results indicated a potential anti-oxidative stress function of the protein ITCH in sugar cataract. The overexpression of ITCH inhibited the apoptosis of HLECs (Fig. 8). Therefore, the upregulation of ITCH may be a potential treatment approach for patients with sugar cataract.

In the present study, although it was verified that osmotic pressure had no significant effect on the results at the RNA level, further experiments were not conducted and thus, this was only a cursory conclusion. Further studies will be 
conducted in the future to investigate the role of osmotic pressure in ITCH, Txnip and Trx in HLECs. In addition, the effect of cell density on the expression of Trx in HLECs was also not studied, which was another limitation of this study, and will be investigated in future studies.

\section{Acknowledgements}

Not applicable.

\section{Funding}

The present study was supported by the National Natural Science Foundation of China (grant no. 81170836) and Clinical Genetics (Ophthalmology), Subject Construction Project of China Medical University (grant no. 3110118049).

\section{Availability of data and materials}

The datasets used and or/analyzed during the present study are available from the corresponding author on reasonable requests.

\section{Authors' contributions}

LFJ designed and performed the experiments, conducted the statistical analysis of the data and drafted the manuscript. WKZ and BL contributed towards the study design. QCY contributed towards the study design and data analysis, revised the manuscript critically for important intellectual content and gave final approval of the version to be published. All authors read and approved the final manuscript and agree to be accountable for all aspects of the research in ensuing that the accuracy or integrity of and part of the work are appropriately investigated and resolved.

\section{Ethics approval and consent to participate}

Not applicable.

\section{Patient consent for publication}

Not applicable.

\section{Competing interests}

The authors declare that they have no competing interests.

\section{References}

1. Fukuoka $\mathrm{H}$ and Afshari NA: The impact of age-related cataract on measures of frailty in an aging global population. Curr Opin Ophthalmol 28: 93-97, 2017.

2. Francis PJ and Moore AT: Genetics of childhood cataract. Curr Opin Ophthalmol 15: 10-15, 2004

3. Andley UP, Tycksen E, McGlasson-Naumann BN and Hamilton PD: Probing the changes in gene expression due to $\alpha$-crystallin mutations in mouse models of hereditary human cataract. PLoS One 13: e0190817, 2018.

4. Bahia S, Blais E, Murugkar S, Chauhan V and Kumarathasan P: Oxidative and nitrative stress-related changes in human lens epithelial cells following exposure to X-rays. Int J Radiat Biol 94: 366-373, 2018.
5. Bhagat AK, Bhardwaj H, Bhardwaj BL, Goyal S, Jaura S and Jain P: Acute bilateral cataract in patient with type 1 diabetes mellitus. J Assoc Physicians India 67: 83, 2019.

6. Mirsky N, Cohen R, Eliaz A and Dovrat A: Featured article: Inhibition of diabetic cataract by glucose tolerance factor extracted from yeast. Exp Biol Med (Maywood) 241: 817-829, 2016.

7. Tinkov AA, Bjørklund G, Skalny AV, Holmgren A, Skalnaya MG Chirumbolo $\mathrm{S}$ and Aaseth J: The role of the thioredoxin/thioredoxin reductase system in the metabolic syndrome: Towards a possible prognostic marker? Cell Mol Life Sci 75: 1567-1586, 2018.

8. Montano SJ, Lu J, Gustafsson TN and Holmgren A: Activity assays of mammalian thioredoxin and thioredoxin reductase: Fluorescent disulfide substrates, mechanisms, and use with tissue samples. Anal Biochem 449: 139-146, 2014.

9. Lu J and Holmgren A: The thioredoxin antioxidant system. Free Radic Biol Med 66: 75-87, 2014.

10. Chen KS and DeLuca HF: Isolation and characterization of a novel cDNA from HL-60 cells treated with 1,25-dihydroxyvitamin D-3. Biochim Biophys Acta 1219: 26-32, 1994.

11. Patwari P, Higgins LJ, Chutkow WA, Yoshioka J and Lee RT: The interaction of thioredoxin with Txnip. Evidence for formation of a mixed disulfide by disulfide exchange. J Biol Chem 281: 21884-21891, 2006.

12. Abderrazak A, Syrovets T, Couchie D, El Hadri K, Friguet B, Simmet T and Rouis M: NLRP3 inflammasome: From a danger signal sensor to a regulatory node of oxidative stress and inflammatory diseases. Redox Biol 4: 296-307, 2015.

13. Nishiyama A, Matsui M, Iwata S, Hirota K, Masutani H, Nakamura H, Takagi Y, Sono H, Gon Y and Yodoi J: Identification of thioredoxin-binding protein-2/vitamin $\mathrm{D}(3)$ up-regulated protein 1 as a negative regulator of thioredoxin function and expression. J Biol Chem 274: 21645-21650, 1999.

14. Pasternak Y, Ohana M, Biron-Shental T, Cohen-Hagai K, Benchetrit $\mathrm{S}$ and Zitman-Gal T: Thioredoxin, thioredoxin interacting protein and transducer and activator of transcription 3 in gestational diabetes. Mol Biol Rep 47: 1199-1206, 2020.

15. Gao C, Huang W, Kanasaki $\mathrm{K}$ and $\mathrm{Xu} \mathrm{Y}$ : The role of ubiquitination and sumoylation in diabetic nephropathy. Biomed Res Int 2014: 160692, 2014.

16. Lorenz S: Structural mechanisms of HECT-type ubiquitin ligases. Biol Chem 399: 127-145, 2018.

17. Michelle C, Vourc'h P, Mignon L and Andres CR: What was the set of ubiquitin and ubiquitin-like conjugating enzymes in the eukaryote common ancestor? J Mol Evol 68: 616-628, 2009.

18. Li W, Bengtson MH, Ulbrich A, Matsuda A, Reddy VA, Orth A, Chanda SK, Batalov S and Joazeiro CA: Genome-wide and functional annotation of human E3 ubiquitin ligases identifies MULAN, a mitochondrial E3 that regulates the organelle's dynamics and signaling. PLoS One 3: e1487, 2008.

19. Aki D, Zhang W and Liu YC: The E3 ligase Itch in immune regulation and beyond. Immunol Rev 266: 6-26, 2015.

20. Otaki Y, Takahashi H, Watanabe T, Funayama A, Netsu S, Honda Y, Narumi T, Kadowaki S, Hasegawa H, Honda S, et al: HECT-type ubiquitin E3 ligase ITCH interacts with thioredoxin-interacting protein and ameliorates reactive oxygen species-induced cardiotoxicity. J Am Heart Assoc 5: e002485, 2016.

21. Han X, Dong XX, Shi MY, Feng L, Wang XL, Zhang JS and Yan QC: SUMOylation and deacetylation affect NF- $\kappa$ B p65 activity induced by high glucose in human lens epithelial cells. Int J Ophthalmol 12: 1371-1379, 2019.

22. Schmittgen TD and Livak KJ: Analyzing real-time PCR data by the comparative C(T) method. Nat Protoc 3: 1101-1108, 2008

23. Park YJ, Oanh NTK, Heo J, Kim SG, Lee HS, Lee H, Lee JH, Kang HC, Lim W, Yoo YS and Cho H: Dual targeting of RIG-I and MAVS by MARCH5 mitochondria ubiquitin ligase in innate immunity. Cell Signal 67: 109520, 2020.

24. Junn E, Han SH, Im JY, Yang Y, Cho EW, Um HD, Kim DK, Lee KW, Han PL, Rhee SG and Choi I: Vitamin D3 up-regulated protein 1 mediates oxidative stress via suppressing the thioredoxin function. J Immunol 164: 6287-6295, 2000.

25. Wang Y, De Keulenaer GW and Lee RT: Vitamin D(3)-upregulated protein-1 is a stress-responsive gene that regulates cardiomyocyte viability through interaction with thioredoxin. J Biol Chem 277: 26496-26500, 2002.

26. Osnes-Ringen Ø, Berg KH, Moe MC, Zetterström C, Røger M and Nicolaissen B: Cell death pattern in lens epithelium of cataract patients. Acta Ophthalmol 94: 514-520, 2016. 
27. Bron AJ, Brown NA, Harding JJ and Ganea E: The lens and cataract in diabetes. Int Ophthalmol Clin 38: 37-67, 1998.

28. Collet JF and Messens J: Structure, function, and mechanism of thioredoxin proteins. Antioxid Redox Signal 13: 1205-1216, 2010.

29. Chen KS and DeLuca HF: Cloning of the human 1 alpha, 25-dihydroxyvitamin D-3 24-hydroxylase gene promoter and identification of two vitamin D-responsive elements. Biochim Biophys Acta 1263: 1-9, 1995.

30. Jeanine CS, Amie DM and Walter HW: Oxidation and nuclear localization of thioredoxin-1 in sparse cell cultures. J Cell Biochem 104:1879-1889, 2008.

31. Zhang X, Zhang JH, Chen XY, Hu QH, Wang MX, Jin R, Zhang QY Wang W, Wang R, Kang LL, et al: Reactive oxygen species-induced TXNIP drives fructose-mediated hepatic inflammation and lipid accumulation through NLRP3 inflammasome activation. Antioxid Redox Signal 22: 848-870, 2015.

32. Oslowski CM, Hara T, O'Sullivan-Murphy B, Kanekura K, Lu S, Hara M, Ishigaki S, Zhu LJ, Hayashi E, Hui ST, et al: Thioredoxin-interacting protein mediates ER stress-induced $\beta$ cell death through initiation of the inflammasome. Cell Metab 16 : 265-273, 2012
33. Bernardini S, Gravina P, Croce N, Perricone R, Knight RA, Valentini A, Melino G and Federici G: Itch gene polymorphisms in healthy population and in patients affected by rheumatoid arthritis and atopic dermatitis. Cell Cycle 7: 3607-3609, 2008.

34. Zhang P, Wang C, Gao K, Wang D, Mao J, An J, Xu C, Wu D, Yu H, Liu JO and Yu L: The ubiquitin ligase itch regulates apoptosis by targeting thioredoxin-interacting protein for ubiquitin-dependent degradation. J Biol Chem 285: 8869-8879, 2010.

35. Mouchantaf R, Azakir BA, McPherson PS, Millard SM, Wood SA and Angers A: The ubiquitin ligase itch is auto-ubiquitylated in vivo and in vitro but is protected from degradation by interacting with the deubiquitylating enzyme FAM/USP9X. J Biol Chem 281: 38738-38747, 2006.

(7) $(-)$ This work is licensed under a Creative Commons Attribution-NonCommercial-NoDerivatives 4.0 International (CC BY-NC-ND 4.0) License. 